\title{
Cost-Effectiveness Analysis of Four Common Diagnostic Methods for Clostridioides difficile Infection
}

\author{
Si Xuan, $\mathrm{MPH}^{1,2}$, Kenneth M. Zangwill, $\mathrm{MD}^{3}$, Weiyi $\mathrm{Ni}, \mathrm{PhD}^{1,2}$, Junjie $\mathrm{Ma}, \mathrm{PhD}^{4}$, and \\ Joel W. Hay, $P h D^{1,2}$

\begin{abstract}
'Leonard D. Schaeffer Center for Health Policy and Economics, University of Southern California, Los Angeles, CA, USA; '²Department of Pharmaceutical and Health Economics, School of Pharmacy, University of Southern California, Los Angeles, CA, USA; ${ }^{3}$ Division of Pediatric Infectious Diseases and Los Angeles Biomedical Research Institute, Harbor-UCLA Medical Center, Torrance, CA, USA; ${ }^{4}$ Department of Pharmacotherapy, University of Utah, Salt Lake City, UT, USA.
\end{abstract}

\begin{abstract}
BACKGROUND: No studies have evaluated the costeffectiveness of single and two-step different diagnostic test strategies for Clostridioides difficile infection (CDI), including direct and indirect costs.

OBJECTIVE: To evaluate the cost-effectiveness of commonly available diagnostic tests for CDI including nucleic acid amplification testing (NAAT) alone, glutamate dehydrogenase followed by enzyme immunoassay for toxin (GDH/EIA), GDH then NAAT (GDH/NAAT), and NAAT then EIA (NAAT/EIA).
\end{abstract}

DESIGN: Decision tree model from the US societal perspective with inputs derived from the literature. Willingness-to-pay threshold was set at \$150,000 per quality-adjusted life year (BALY) gained. To assess the impact of uncertainty in model inputs on the findings, we performed one-way and probabilistic sensitivity analyses.

PARTICIPANTS: We conducted the analysis to represent a population aged 65 years old with diarrhea who received a CDI diagnostic test.

MAIN MEASURES: Incremental cost-effectiveness ratios (ICER) and incremental net monetary benefits (INMB).

KEY RESULTS: NAAT alone was the most cost-effective approach overall; GDH/NAAT was the most cost-effective two-step option. NAAT alone led to the highest QALYs gained, at an incremental cost of \$54,547 (vs. GDH/ NAAT), \$55,410 (vs. GDH/EIA), and \$50,231 (vs. NAAT/EIA) per QALY gained. NAAT/EIA was not costeffective compared to any other strategy. GDH/NAAT resulted in a higher QALY compared to GDH/EIA, at an incremental cost of $\$ 96,841$ per QALY gained. Variability in the likelihood of comorbidities, CDI probability, and age at disease onset did not substantially change the results. One-way sensitivity analyses showed that results were most sensitive to likelihood of recurrence, followed by CDI mortality rate and probability of severe CDI. Probabilistic sensitivity analyses explored known uncertainties in the base case and confirmed the robustness of the results.

Electronic supplementary material The online version of this article (https://doi.org/10.1007/s11606-019-05487-5) contains supplementary material which is available to authorized users

Received December 17, 2018

Revised July 8, 2019

Accepted September 23, 2019

Published online February 3, 2020
CONCLUSIONS: NAAT alone and GDH/NAAT (among the two-step options) were the most cost-effective diagnostic test approaches for CDI.

KEY WORDS: Clostridioides difficile infection; diagnostic methods; costeffectiveness analysis.

$\mathrm{J}$ Gen Intern Med 35(4):1102-10

DOI: $10.1007 / \mathrm{s} 11606-019-05487-5$

(c) Society of General Internal Medicine 2020

\section{INTRODUCTION}

Clostridioides difficile infection (CDI) is the leading cause of healthcare-associated diarrhea in the United States (US) and is associated with significant morbidity and mortality. ${ }^{1,2}$ The Centers for Disease Control and Prevention (CDC) estimated that nearly 500,000 patients had CDI with 29,000 attributable deaths in the US in 2011. ${ }^{1}$ CDI imposes a substantial economic burden for individuals and healthcare systems; an estimated $\$ 750$ million to $\$ 3.2$ billion in direct and indirect costs annually. ${ }^{3}$ Further, CDC lists CDI as an "urgent" threat to public health that needs aggressive action towards its detection, treatment, and prevention. ${ }^{4}$

Prompt and accurate diagnosis of CDI is essential for proper and rapid treatment to prevent disease progression and for timely infection control in healthcare settings. In March 2018, an updated US clinical practice guideline was published which discussed commonly used diagnostic tests for CDI. ${ }^{5}$ Singly or in combination, four CDI testing strategies were recommended including (1) nucleic acid amplification tests (NAAT) alone; (2) glutamate dehydrogenase (GDH) plus enzyme immunoassay (EIA) for toxins A and B; (3) GDH plus EIA, arbitrated by NAAT; and (4) NAAT plus EIA. Any of the three multistep algorithms was recommended for use for detecting patients at increased risk for clinically significant CDI. NAAT alone was added as an option for patients likely to have CDI based on clinical symptoms. ${ }^{5}$

This guideline acknowledges that there is no consensus on the optimal laboratory testing method. Many factors contribute to decision-making about test adoption including local availability of specific tests, laboratory workflow, and cost-related impacts. Indeed, the relative cost-effectiveness of available diagnostic 
options has not been comprehensively assessed. Such work typically does not include a full range of clinically available test choices, ${ }^{6-9}$ outcomes are limited to costs per case, and no prior studies have assessed incremental cost per quality-adjusted life year (QALY) impacts, an important measure for policy development, in addition to clinical considerations. We evaluated the cost-effectiveness of multiple recommended CDI laboratorybased diagnostic approaches in a US population cohort.

\section{METHODS}

\section{Model Overview}

A cost-effectiveness analysis (CEA) was conducted per the basic principles of CEA as outlined by Gold et al. ${ }^{10}$ and Neumann et al. ${ }^{11} \mathrm{~A}$ decision tree was constructed to compare four CDI diagnostic approaches, from a US societal perspective (Excel 2015, Microsoft, Seattle, WA): (1) NAAT alone; (2) GDH/EIA (stool samples first tested with GDH and positive specimens then tested with EIA); (3) NAAT/EIA (stool samples first tested with NAAT and positive specimens then tested with EIA); and (4) GDH/NAAT (stool samples first tested with GDH and positive specimens then tested with NAAT). The patient modeled in the study was a 65-year-old adult in the US with diarrhea (the average age of CDI patients is 65 years). ${ }^{2}{ }^{3}$ The model's time horizon is 19 years, the average lifespan of the modeled patient. ${ }^{12}$ Both costs and QALYs were discounted at $3 \%$ per year. ${ }^{13}$ Incremental cost-effectiveness ratio (ICER) and incremental net monetary benefit (INMB) were calculated. In base case, we used a societal willingness-to-pay (WTP) threshold of $\$ 150,000$ per QALY; an intervention is considered cost-effective if ICER is below the WTP threshold. ${ }^{14}$ We extrapolated the model to the 2017 US 65-year-old cohort $(3,567,978)^{15}$ and a prevalence of acute diarrheal disease of $2.4 \% .^{16}$

\section{Model Structure}

Figure 1 details the structure of the clinical decision tree. Patients with diarrhea symptoms who had a CDI diagnostic test comprised the starting cohort. Patients were assumed to be treated if NAAT was positive (NAAT alone), or both tests were positive (in the two-step algorithms). CDI was defined as mild-moderate or severe as per the Infectious Diseases Society of America CDI guideline. ${ }^{5}$ Patients with false-negative tests were assumed to be treated and modeled to either have ongoing mild-moderate CDI or exhibited progression to severe CDI. The drug choice and duration of antimicrobial treatment are as recommended in the US guideline, ${ }^{5}$ and our justification to not model bezlotoxumab and fecal microbiota for transplantation are summarized in online Supplementary Table S1. Following treatment, patients were considered to (1) be successfully treated (with the possibility of recurrence), (2) have died from CDI, or (3) be an acute treatment failure. Patients with the treatment failure were given next-line treatment. We modeled up to two recurrences following the initial episode based on the current guideline. ${ }^{5}$

\section{Model Parameters}

Probability estimates, utilities, costs, and their ranges are summarized in Table 1.

\section{Probabilities}

Sensitivity and specificity rates of GDH/NAAT and GDH/EIA were derived from a prospective multicenter population-based study that evaluated commonly used CDI testing methods. Sensitivity and specificity rates of NAAT alone, EIA, and GDH were derived from the guideline for CDI diagnostics. ${ }^{29}$ Since there is a lack of studies reporting performance of NAAT/EIA, we applied the calculations of net sensitivity and net specificity of sequential testing to calculate these parameters for NAAT/EIA (online Supplementary Table S2). The positive predictive value and negative predictive value for the single assay and combinations of assays were calculated based on their sensitivity and specificity using the Bayes' rule of conditional probabilities ${ }^{31,32}$ (online Supplementary Table S2). The probability of CDI was based on a nationwide cohort of patients with diarrhea aged 65 years and older in the US. ${ }^{17}$ There are limited robust data on age-specific mortality due to CDI. We derived CDI-attributable mortality for the initial episode in patients aged 65 and over from nationwide prospective surveillance ${ }^{19}$ and the mortality rates for recurrences from a national cohort of veterans with recurrent disease. ${ }^{20}$ The probability estimates regarding patient-level responses to antimicrobial therapy were derived from clinical trial data and population-based studies (Table 1).

\section{Utilities}

The efficacy outcome was measured as QALY, which is a standard measure that incorporates the impact of a healthcare intervention on both length and quality of life. QALY was calculated as the product of the utility of a particular health condition and time experiencing that health condition. Utility assesses the quality of life in different health conditions and ranges from 0 (death) to 1 (perfect health). Within the decision tree, patients were modeled in one of six health conditions: healthy without CDI, cured from either mild-moderate CDI, or severe CDI, a mild-moderate post-colectomy health condition, a severe post-colectomy health condition, and death. Utility measures for CDI health states have not been established by commonly accepted techniques; we used utility measures for colitis to estimate the utilities for $\mathrm{CDI}^{34}$ (Table 1). The utility measures and calculations of QALYs are also summarized in online Supplementary Appendix, "1.3 Calculation of QALYs."

\section{Costs}

All costs were adjusted to 2017 US dollars using the US Consumer Price Index medical care component reported by the US Bureau of Labor Statistics. ${ }^{39}$ The costs were taken from a societal perspective, which included direct costs such as costs of diagnostic tests, and indirect costs associated with lost work productivity due to CDI (Table 1). Drug costs were obtained from the 
(a) NAAT alone



(b) Two-step disagnostic strategies

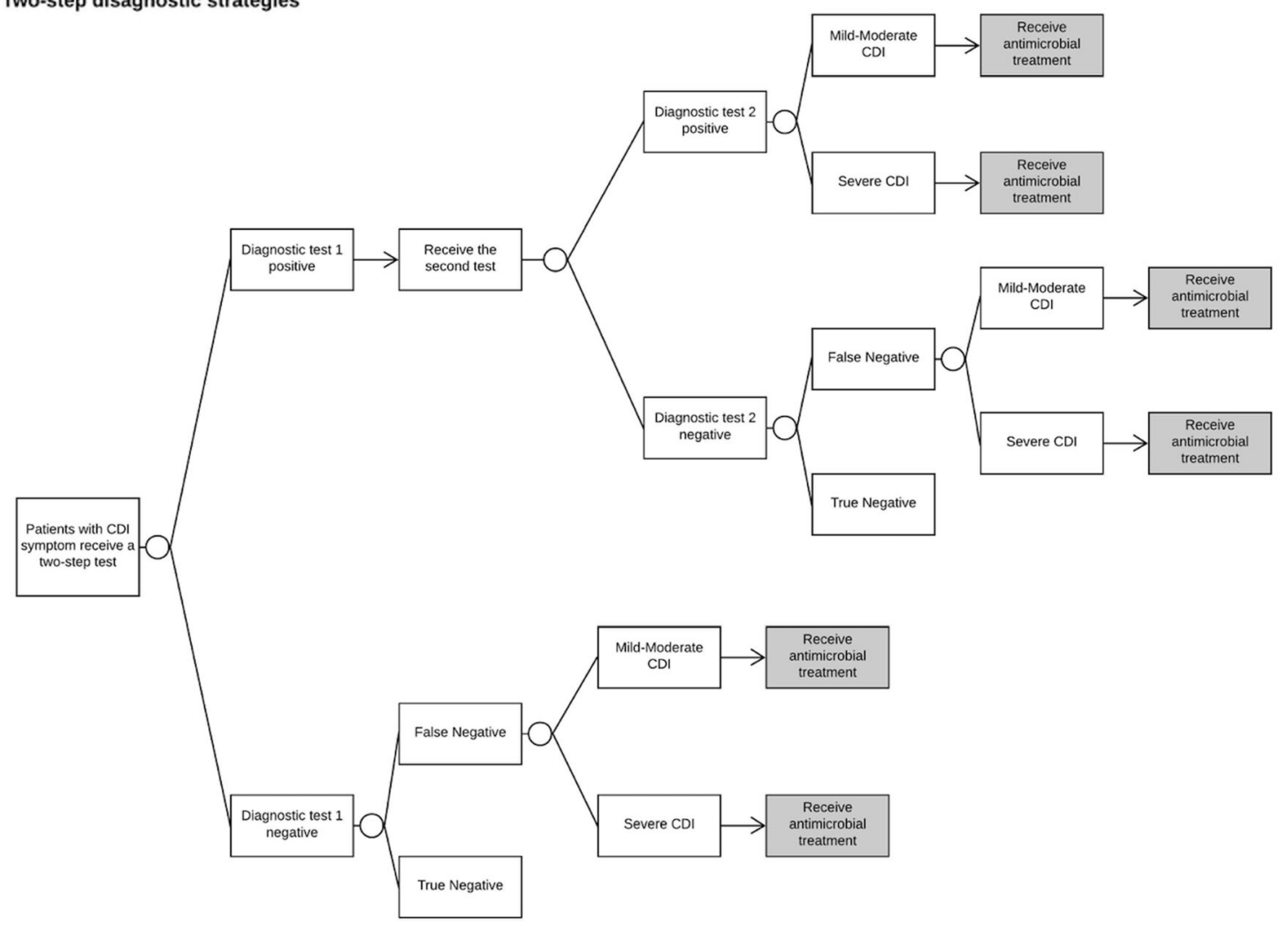

Figure 1 Decision tree of CDI diagnostic strategies. a Decision tree of NAAT alone. b Decision tree of two-step diagnostic strategies. Antimicrobial treatment: patients who had positive tests or false-negative tests would be treated. Following treatment, patients were either deemed cured, death, or a treatment failure. Patients who failed to response to the current treatment would receive next-line treatment. Patients who were deemed cured would either cured without recurrence or develop recurrence. Recurrence was assumed that patients successfully treated who then developed a recurrence at least 4 weeks later. We modeled up to two recurrences. Within the decision tree, patients were modeled in one of six health outcomes: healthy without CDI (true negative), cured (without further recurrence) from mild-moderate CDI, cured (without further recurrence) from severe CDI, a mild-moderate post-colectomy health condition, a severe post-colectomy health condition, and death. CDI, Clostridioides difficile infection; NAAT, nucleic acid amplification test. 
Table 1 Clinical, Laboratory, Utility, and Cost Model Input Parameters

\begin{tabular}{|c|c|c|c|c|}
\hline Parameters & Base case & Range & $\begin{array}{l}\text { Distribution } \\
\text { type* }^{*}\end{array}$ & Reference \\
\hline Probabilities $(\%)$ & $\%$ & $\begin{array}{l}95 \% \text { confidence } \\
\text { interval }\end{array}$ & & \\
\hline Any CDI & 13.6 & $10.3-16.8$ & Beta & 17 \\
\hline Severe CDI & 23.8 & $19.0-28.5$ & Beta & 18 \\
\hline CDI-attributable death (initial CDI) & 7.3 & $5.7-8.9$ & Beta & 19 \\
\hline Death (first CDI recurrence) & 8.3 & $7.2-10.0$ & Beta & 20 \\
\hline Death (second CDI recurrence) & 4.2 & $2.3-5.5$ & Beta & 20 \\
\hline Death (subtotal colectomy) & 38.7 & $37.5-39.9$ & Beta & 21,22 \\
\hline Subtotal colectomy & 0.16 & $0.06-0.25$ & Beta & 23 \\
\hline Cure (mild-moderate CDI, vancomycin) & 83.9 & $81.0-86.7$ & Beta & 24,25 \\
\hline Cure (mild-moderate CDI, fidaxomicin) & 92.0 & 89.9-94.1 & Beta & 25 \\
\hline Cure (severe CDI, vancomycin) & 88.6 & $86.1-91.1$ & Beta & 24,25 \\
\hline Cure (severe CDI, fidaxomicin) & 82.1 & $79.1-85.1$ & Beta & 25 \\
\hline Cure (vancomycin taper and pulsed) & 69.0 & $61.9-76.1$ & Beta & 26 \\
\hline Cure (vancomycin + rifaximin) & 53.0 & $35.7-70.3$ & Beta & 27 \\
\hline Recurrence (mild-moderate CDI, vancomycin) & 24.4 & $21.0-27.8$ & Beta & 24,25 \\
\hline Recurrence (mild-moderate CDI, fidaxomicin) & 16.8 & $13.9-19.7$ & Beta & 25 \\
\hline Recurrence (severe CDI, vancomycin) & 26.6 & $23.2-30.1$ & Beta & 24,25 \\
\hline Recurrence (severe CDI, fidaxomicin) & 13.0 & $10.4-15.6$ & Beta & 25 \\
\hline $\begin{array}{l}\text { Severe comorbidities and complications (post- } \\
\text { colectomy) }\end{array}$ & 80.0 & $68.8-91.2$ & Beta & 21,22 \\
\hline 1 st recurrence $(\mathrm{CDI})$ & 20.9 & $20.3-21.5$ & Beta & 1 \\
\hline Cure (IV metronidazole + vancomycin) & 84.1 & $73.3-94.9$ & Beta & 28 \\
\hline NAAT sensitivity & 95.0 & $92.0-97.0$ & Beta & 29 \\
\hline NAAT specificity & 98.0 & $97.0-99.0$ & Beta & 29 \\
\hline GDH sensitivity & 96.0 & $86.0-99.0$ & Beta & 29 \\
\hline GDH specificity & 96.0 & $91.0-98.0$ & Beta & 29 \\
\hline EIA sensitivity & 57.0 & $51.0-63.0$ & Beta & 29 \\
\hline EIA specificity & 99.0 & $98.0-99.9$ & Beta & 29 \\
\hline GDH/EIA sensitivity & 57.0 & $53.9-60.0$ & Beta & 30 \\
\hline GDH/EIA specificity & 99.4 & $99.3-99.6$ & Beta & 30 \\
\hline GDH/NAAT sensitivity & 91.5 & $89.6-93.1$ & Beta & 30 \\
\hline GDH/NAAT specificity & 98.0 & $97.7-98.3$ & Beta & 30 \\
\hline NAAT/EIA sensitivity & 54.2 & N/A & Invariant $^{\dagger}$ & $\begin{array}{l}\text { Calculated }^{31,32} \text { (online } \\
\text { Supplementary Table S1) }\end{array}$ \\
\hline NAAT/EIA specificity & 99.9 & $\mathrm{~N} / \mathrm{A}$ & Invariant & $\begin{array}{l}\text { Calculated } \\
\text { Supplementary Table S1) }\end{array}$ \\
\hline Utilities & & $\begin{array}{l}95 \% \text { confidence } \\
\text { interval }\end{array}$ & & \\
\hline Healthy (age 65) & 0.88 & $0.86-0.90$ & Beta & 33 \\
\hline Mild-moderate CDI & 0.78 & $0.43-1.13$ & Beta & 34 \\
\hline Severe CDI & 0.68 & $0.30-1.05$ & Beta & 34 \\
\hline Mild-moderate post-colectomy & 0.85 & $0.84-0.86$ & Beta & 33 \\
\hline Severe post-colectomy & 0.75 & $0.68-0.81$ & Beta & 33 \\
\hline Death & 0 & $\mathrm{~N} / \mathrm{A}$ & $\mathrm{N} / \mathrm{A}$ & \\
\hline Direct medical cost & 2017 US\$ & Range & & \\
\hline Hospitalization cost & $\$ 12,584.16$ & $\begin{array}{l} \pm 0.25(\$ 9438.12- \\
15,730.20)\end{array}$ & Gamma & 3 \\
\hline Subtotal colectomy & $\$ 27,604.18$ & $\begin{array}{l} \pm 0.25(\$ 20,703.14 \\
34,505.23)\end{array}$ & Gamma & 35 \\
\hline Fidaxomicin $200 \mathrm{mg}$ & $\$ 2545.60$ & N/A & Invariant & 36 \\
\hline Vancomycin $125 \mathrm{mg}$ & $\$ 863.20$ & $\mathrm{~N} / \mathrm{A}$ & Invariant & 36 \\
\hline Vancomycin tapered/pulsed & $\$ 1467.44$ & $\mathrm{~N} / \mathrm{A}$ & Invariant & 36 \\
\hline Rifaximin & $\$ 1636.80$ & $\mathrm{~N} / \mathrm{A}$ & Invariant & 36 \\
\hline Vancomycin + IV metronidazole & $\$ 132$ & $\mathrm{~N} / \mathrm{A}$ & Invariant & 36 \\
\hline NAAT & $\$ 40.77$ & $\mathrm{~N} / \mathrm{A}$ & Invariant & 6,8 \\
\hline GDH & $\$ 13.87$ & $\mathrm{~N} / \mathrm{A}$ & Invariant & 6,8 \\
\hline EIA & $\$ 11.30$ & $\mathrm{~N} / \mathrm{A}$ & Invariant & 6,8 \\
\hline $\begin{array}{l}\text { Long-term post-colectomy costs: } 1 \text { or } 2 \text { chronic } \\
\text { conditions (annual) }\end{array}$ & $\$ 21,521.69$ & $\begin{array}{l} \pm 0.25(\$ 16,141.27- \\
26,902.11)\end{array}$ & Gamma & 37 \\
\hline $\begin{array}{l}\text { Long-term post-colectomy costs: } 2+\text { chronic con- } \\
\text { dition (annual) }\end{array}$ & $\$ 46,842.94$ & $\begin{array}{l} \pm 0.25(\$ 35,132.21- \\
58,553.68)\end{array}$ & Gamma & 37 \\
\hline Costs associated with adverse events & $\$ 2.88$ & $\pm 0.25(\$ 2.16-3.60)$ & Gamma & 36,38 \\
\hline Indirect costs & 2017 US\$ & & & \\
\hline $\begin{array}{l}\text { Inpatient treatment (IV metronidazole }+ \\
\text { vancomycin, fidaxomicin, or vancomycin) }\end{array}$ & $\$ 2257.92$ & N/A & Invariant & 39 \\
\hline Inpatient treatment (vancomycin tapered/pulsed) & $\$ 7056.00$ & $\mathrm{~N} / \mathrm{A}$ & Invariant & 39 \\
\hline Hospitalization (subtotal colectomy) & $\$ 5644.80$ & $\mathrm{~N} / \mathrm{A}$ & Invariant & 39 \\
\hline Travel, wait, and screen test & $\$ 141.12$ & $\mathrm{~N} / \mathrm{A}$ & Invariant & 39 \\
\hline
\end{tabular}

NAAT nucleic acid amplification test, GDH glutamate dehydrogenase, EIA enzyme immunoassay, CDI Clostridioides difficile infection

*A beta distribution was assumed for binomial data. The beta distribution characterizes the distribution of continuous probabilities, is constrained on the interval 0-1, and is parameterized by two positive parameters, alpha and beta. A gamma distribution was assumed for cost data. The gamma distribution is constrained on the interval 0 to positive infinity, is conjugate to the Poisson, and is characterized by two parameters, denoted as alpha and beta tParameters were not varied in the probabilistic sensitivity analyses 
Federal Supply Schedule drug prices. ${ }^{36}$ Adverse events from antimicrobial treatments were assumed to be mild-moderate with an average $5 \%$ prevalence among all patients. ${ }^{38}$ The hospitalization cost for CDI was based on data from the Healthcare Cost and Utilization Project (HCUP). ${ }^{3}$ The annual costs associated with multiple chronic conditions were derived from a study that estimated 1-year total health care costs in the Medicare population stratified by the number of comorbidities ${ }^{37}$ and then discounted at 3\% over 19 years. Relevant time costs considered traveling, waiting, diagnostic testing, receiving inpatient treatments, and hospitalization due to subtotal colectomy. The indirect costs of time lost were estimated from the average hourly compensation rate from the US Bureau of Labor Statistics. ${ }^{39}$

\section{Sensitivity Analyses}

One-way sensitivity analyses were performed on probabilities, utilities, and costs to assess the independent impact of individual input uncertainties and overall robustness of the base case model. The input parameters in the base case were varied by their corresponding $95 \%$ confidence intervals (CIs), or by $\pm 25 \%$ when $95 \%$ CIs were not available in the literature. Tornado diagrams were plotted in the order from most to the least sensitive parameter. We performed a probabilistic sensitivity analysis (PSA) using 1000 Monte Carlo cohort-based simulations to simultaneously assess uncertainty in model input parameters. The distribution for the model inputs was based on clinical guideline recommendations ${ }^{13}$ (online Supplementary Appendix, "3 Probabilistic sensitivity analysis"). Cost-effectiveness acceptability curves were plotted to indicate the probability of a strategy being cost-effective over the range of WTP thresholds ${ }^{13}$ (online Supplementary Figure S2).

\section{Scenario Analyses}

In the base case, we assumed all patients had a life span equivalent to that predicted for a healthy population. We did scenario analyses where all CDI patients assumed to have comorbidities resulting in a diminished life expectancy of 17,15 , or 13 years. Sensitivity to age at disease onset was tested by varying baseline age to 75 years and 85 years. Time spent in different health states was also varied at $\pm 25 \%$. In addition, sensitivity to the CDI probability was examined by varying the baseline likelihood by \pm $10 \%, 20 \%, 30 \%$, and $40 \%$.

\section{RESULTS}

\section{Base Case Analysis}

When extrapolated to the US 65-year-old cohort with diarrhea, our model predicted a total of 11,646 CDI cases, including 8874 mild-moderate and 2772 severe CDI cases (Table 2). NAAT alone was associated with the highest total costs, driven primarily by costs associated with unnecessary treatment, which was mainly due to its lower positive predictive value when compared to the other test options. Over the 19-year time horizon,
Table 2 The Number of Predicted CDI Cases and Associated Costs in the US 65-Year-Old Cohort with Diarrhea (2017)

\begin{tabular}{llll}
\hline \hline & $\begin{array}{l}\text { Total } \\
\text { cases }\end{array}$ & Total costs & $\begin{array}{l}\text { Costs per } \\
\text { patient }\end{array}$ \\
\hline CDI & 11,646 & $\$ 180,701,215$ & $\$ 15,516$ \\
Mild-moderate & 8874 & $\$ 101,499,680$ & $\$ 11,438$ \\
$\begin{array}{l}\text { CDI } \\
\text { Severe CDI }\end{array}$ & 2772 & $\$ 79,201,535$ & $\$ 28,575$ \\
\hline
\end{tabular}

CDI Clostridioides difficile infection

compared with NAAT alone, each of the three two-step approaches would save between $\$ 22.4$ and \$24.4 million in total costs (online Supplementary Table S8). This is driven mainly by savings associated with less antimicrobial treatment and likelihood of multiple recurrences of disease, without surgery.

Our primary cost-effectiveness measure is ICER, a function of total costs and generated QALYs for the tests being compared (online Supplemental 1.4 Calculation of ICER). In the base case analysis, GDH/EIA and NAAT alone had the lowest and highest total costs per 1000 patients, respectively (Table 3). Generated QALYs for each two-step diagnostic test option were similar, and all were less than that of NAAT alone. As noted in Table 3, despite its higher incurred costs, NAAT alone is the most cost-effective approach among the four diagnostic strategies; ICERs ranged from \$50,231 to $\$ 55,410$ per QALY gained compared to the two-step options. And for each comparison, the incurred costs of NAAT alone per additional QALY gained were below our WTP threshold of $\$ 150,000$ per QALY gained and thus cost-effective.

Comparing the three two-step approaches only, use of GDH/NAAT led to more timely treatment due to fewer false negative tests resulting in slightly higher QALYs than GDH/ EIA. Costs of GDH/NAAT per additional QALY gained was well below the WTP threshold, i.e., cost-effective. NAAT/EIA was the most expensive and least effective therefore not preferred. The cost-effectiveness superiority of NAAT (overall) and GDH/NAAT over the other two-step choices were further corroborated by positive INMBs in the above two-way comparisons. Extrapolated to the entire US 65-year-old cohort with diarrhea, the INMBs of NAAT alone over each of the three two-step options were $\$ 41$ million to $\$ 44$ million over the 19-year time horizon (Table 3).

\section{Sensitivity Analyses}

Model inputs with the greatest impact on the ICERs are shown in Figure 2 and online Supplementary Figure S1. Variability in the probability of recurrence among mild-moderate patients had the greatest impact on the ICERs, in all comparisons between NAAT alone and two-step options (Fig. 2). A decrease in the probability of recurrence and increase in the CDIattributable mortality rate substantially increased the incremental cost per QALY gained by NAAT alone. When the probability of recurrence was set to $21 \%$ (low value; Table 1), or the CDI-attributable mortality rate to $8.9 \%$ (high value; Table 1), the ICERs of NAAT alone over two-step 
Table 3 Cost-Effectiveness Results in Base Case Model $($ WTP Threshold $=\$ \mathbf{1 5 0 , 0 0 0})$

\begin{tabular}{|c|c|c|c|c|c|c|}
\hline Tests & $\begin{array}{l}\text { Total QALYs } \\
\text { per 1000 } \\
\text { patients }\end{array}$ & $\begin{array}{l}\text { Total costs per } 1000 \\
\text { patients, } 2017 \text { US\$ }\end{array}$ & $\begin{array}{l}\text { Test } \\
\text { comparisons* }\end{array}$ & $\begin{array}{l}\text { ICER (cost per } \\
\text { additional QALY } \\
\text { gained) }\end{array}$ & $\begin{array}{l}\text { INMB (per } \\
1000 \text { patient) }\end{array}$ & $\begin{array}{l}\text { INMB (in the US 65- } \\
\text { year-old cohort with di- } \\
\text { arrhea) }\end{array}$ \\
\hline \multirow{6}{*}{$\begin{array}{l}\text { NAAT } \\
\text { alone } \\
\text { GDH/ } \\
\text { NAAT } \\
\text { GDH/ } \\
\text { EIA } \\
\text { NAAT/ } \\
\text { EIA }\end{array}$} & $13,592.86$ & $\$ 2,538,601$ & $\begin{array}{l}\text { NAAT alone vs. } \\
\text { GDH/NAAT }\end{array}$ & $\$ 54,547$ & $\$ 481,627$ & $\$ 41,242,471$ \\
\hline & $13,587.81$ & $\$ 2,263,377$ & $\begin{array}{l}\text { NAAT alone vs. } \\
\text { GDH/EIA }\end{array}$ & $\$ 55,410$ & $\$ 487,215$ & $\$ 41,720,978$ \\
\hline & $13,587.71$ & $\$ 2,253,197$ & $\begin{array}{l}\text { NAAT alone vs. } \\
\text { NAAT/EIA }\end{array}$ & $\$ 50,231$ & $\$ 519,132$ & $\$ 44,454,027$ \\
\hline & $13,587.66$ & $\$ 2,277,229$ & $\begin{array}{l}\text { GDH/NAAT vs. } \\
\text { GDH/EIA }\end{array}$ & $\$ 96,841$ & $\$ 5588$ & $\$ 478,508$ \\
\hline & & & $\begin{array}{l}\text { GDH/NAAT vs. } \\
\text { NAAT/EIA }\end{array}$ & $\begin{array}{l}\text { NAAT/EIA } \\
\text { dominated }^{\dagger}\end{array}$ & $\$ 37,504$ & $\$ 3,211,556$ \\
\hline & & & $\begin{array}{l}\text { GDH/EIA vs. } \\
\text { NAAT/EIA }\end{array}$ & $\begin{array}{l}\text { NAAT/EIA } \\
\text { dominated }^{\dagger}\end{array}$ & $\$ 31,916$ & $\$ 2,733,049$ \\
\hline
\end{tabular}

QALY quality-adjusted life year, WTP willingness to pay, ICER incremental cost-effectiveness ratio, INMB incremental net monetary benefit; NAAT nucleic acid amplification test, GDH glutamate dehydrogenase, EIA enzyme immunoassay

*NAAT alone vs. NAAT/EIA = (NAAT costs - NAAT/EIA costs) / (NAAT QALYs - NAAT/EIA QALYs). NAAT alone vs. GDH/EIA = (NAAT costs GDH/EIA costs) / (NAAT QALYs - GDH/EIA QALYs). NAAT alone vs. GDH/NAAT = (NAAT costs - GDH/NAAT costs) / (NAAT QALYs - GDH/NAAT QALYs). GDH/NAAT vs. GDH/EIA = (GDH/NAAT costs - GDH/EIA costs $) /($ GDH/NAAT QALYs - GDH/EIA QALYs)

†Implies greater cost and less effectiveness; compared with GDH/NAAT and GDH/EIA, NAAT/EIA dominated

options exceeded the WTP threshold. With a probability of severe CDI of 19\% (low value; Table 1), NAAT alone and GDH/NAAT were no longer cost-effective overall and among two-step options, respectively (Fig. 2 and online Supplementary Figure S1; online Supplementary Appendix, "2 One-way sensitivity analysis").]->

The PSA results confirm the robustness of the base case analysis in that NAAT alone remained the most cost-effective among the four strategies. Compared with each of the three two-step approaches, the probability of NAAT alone being cost-effective was $45-50 \%$ with a WTP over \$50,000/QALY gained and was $\sim 90 \%$ with an WTP over $\$ 150,000$ (online Supplementary Figure S2a-c). When GDH/NAAT vs. GDH/ EIA was evaluated, GDH/NAAT had a $\sim 61 \%$ probability of being cost-effective at the WTP threshold of $\$ 150,000$, and the probability reached to $80 \%$ when the WTP increased to $\$ 300,000$ (online Supplementary Figure S2d).

\section{Scenario Analyses}

NAAT alone remained the most cost-effective approach when (1) the CDI probability varied from 10 to $40 \%$ (online Supplementary Table S9); (2) anticipated life expectancy reflecting the presence of comorbidities was 17,15 , or 13 years (online Supplementary Table S10); (3) when the CDI age of onset was changed to 75 and 85 years of age (online Supplementary Table S10); and (4) when the pre-defined time spent in different health states varied by $\pm 25 \%$ (online Supplementary Table S10).

\section{DISCUSSION}

We present here the first data on the relative cost-effectiveness of four recommended CDI diagnostic test options; the evaluation of which included direct and indirect costs and QALYs.
Our data suggest that NAAT alone was the most cost-effective strategy despite an important clinical limitation related to its problematic positive predictive value. ${ }^{29}$ The overall diagnostic performance of NAAT alone, however, facilitates more costeffective care resulting in higher QALYs than any of the twostep approaches. Among the three two-step options, we find that GDH/NAAT was the most cost-effective although the differences between these options were small. It should be noted that the improved cost-effectiveness of NAAT over GDH/NAAT was demonstrable, but not impressively different, as per the ICER comparisons. Similarly, our INMB results paralleled the ICER data indicating cost-effectiveness for certain of the testing options. We provide in this report the total costs and incremental net monetary benefit of each test we find to be cost-effective, when applied to the US population cohort of those 65 years of age with diarrhea.

We appreciate that NAAT alone option is not among the preferred options as a "best performing" test choice as described in the 2018 IDSA CDI guideline. It is, however, a first option if high sensitivity is desired. These are both purely clinical determinations and reasonable as such. It is important to acknowledge that diagnostic test choices may be driven by individual patient factors and/or infection prevention considerations - situations for which high sensitivity may be desired. Such factors cannot be easily integrated into recommendations at the national level. As such, we believe our economic data results, which include clinical eventualities, may prove useful as national specialty organizations, institutions, and healthcare systems consider among diagnostic laboratory options to confirm clinical CDI.

We subjected our base case findings to robust one-way and probabilistic sensitivity analyses given that some of our model estimates vary in the literature and there is wide variation in clinical practice regarding medical and surgical management. These analyses revealed the probability of CDI recurrence, 
(a) NAAT alone vs. GDH/EIA

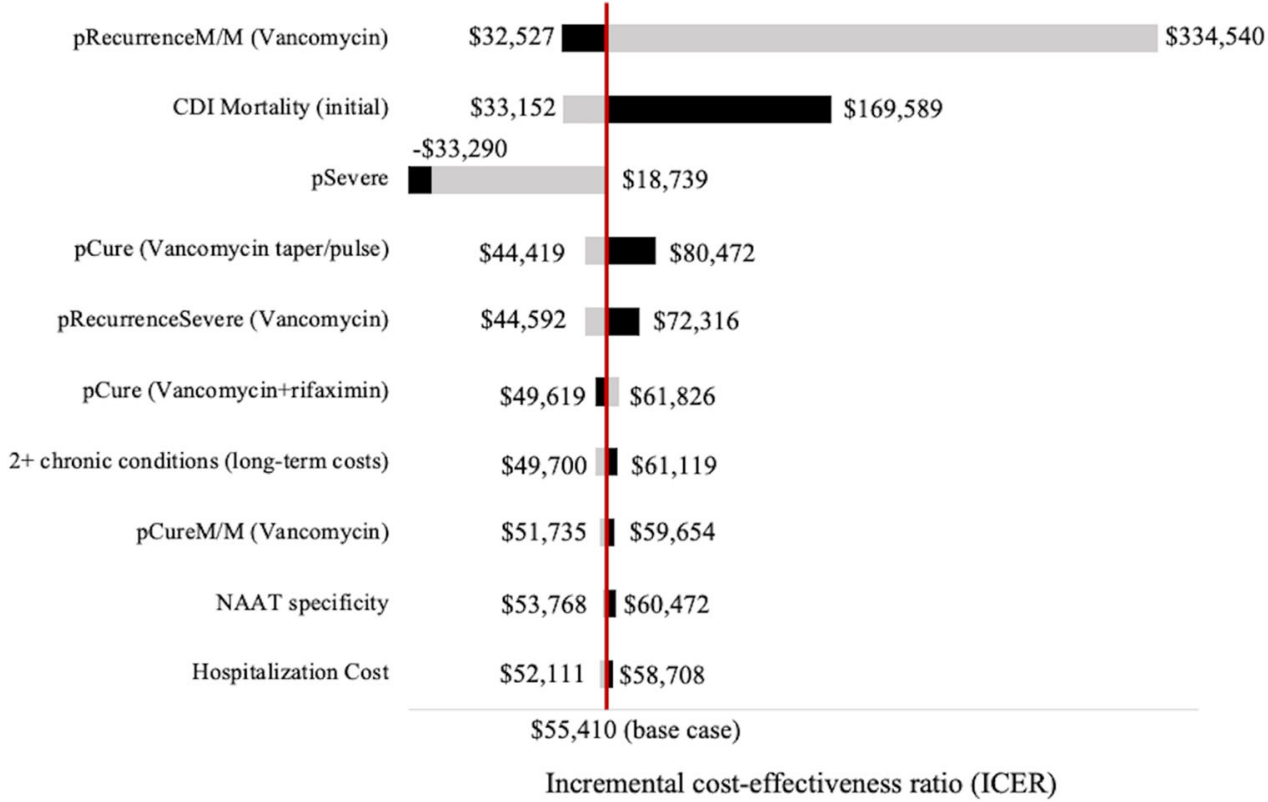

Low value of base case $\quad$ High value of base case

(b) NAAT alone vs. GDH/NAAT



Figure 2 One-way sensitivity analysis tornado diagrams of the ten parameters with the greatest impact on the ICER of NAAT alone compared with each of the two-step options. a NAAT alone vs. GDH/EIA. b NAAT alone vs. GDH/NAAT. c NAAT alone vs. NAAT/EIA. All probabilities and utilities were varied by their corresponding $95 \%$ confidence interval (CI). All cost estimates were varied by $\pm 25 \%$. Low value of base case means that an input parameter was varied using lower level of $95 \%$ CI or - 25\%; high value of base case means that an input parameter was varied using upper level of $95 \%$ CI or $+25 \%$. CDI, Clostridioides difficile infection; NAAT, nucleic acid amplification test; GDH, glutamate dehydrogenase; EIA: enzyme immunoassay; pSevere, probability of having severe CDI; pRecurrenceM/M (vancomycin), probability of having recurrent in mild-moderate CDI; pCure (vancomycin + rifaximin), probability of cure of vancomycin and rifaximin; pRecurrenceSevere (vancomycin), probability of having recurrent in severe CDI; pCureM/M (vancomycin), probability of cure of vancomycin in mild-moderate CDI patients; pCure (vancomycin taper/pulse), probability of cure of tapered and pulsed course of vancomycin; $\mathrm{pCureM/M}$ (fidaxomicin), probability of cure of fidaxomicin in mild-moderate CDI patients; 2+ chronic conditions (long-term costs), long-term costs for patients who survived from subtotal colectomy and had more than 2 chronic conditions; CDI Mortality (initial), CDI-attributable mortality rate for the initial CDI episode. 
severe CDI, and CDI-attributable mortality as the most important drivers of the final cost-effectiveness estimate for the studied diagnostic tests. That these particular outcomes are so impactful is not surprising. It is also notable, as seen in the one-way analyses, that their individual impact varied substantially when tested at reasonable clinical probability limits. The probabilistic analyses, however, suggest a high probability of effectiveness at thresholds well below our WTP threshold in the base case. Our base case results are based on a WTP threshold of $\$ 150,000$; we appreciate there is debate on the appropriate threshold in such analyses. ${ }^{14,40}$

Various studies have assessed the cost-effectiveness of CDI treatment; however, our findings address an important data gap on the cost-effectiveness of CDI diagnostics, specifically. Previous economic studies of CDI are limited to evaluation of hospitalization $\operatorname{costs}^{6,7}$ and no studies assessed ICERs of diagnostic methods. ${ }^{8,9}$ In addition to inpatient costs, we also included costs of time lost due to CDI, as well as long-term costs related to comorbidities after hospital discharge. Time horizons in previous studies were generally 1 year or less; we included lifetime costs and outcomes from a societal perspective. Using published literature and plausible clinical outcomes, we believe our cost-effectiveness analysis adds significant breadth to the existing literature on CDI diagnostics. Our model allows us to quantify the economic impacts of the CDI diagnostic options described in the guideline to reach a conclusion of supporting use of NAAT alone overall and GDH/ NAAT among two-step options. These results contribute to existing clinical findings and the potential utility of our data is made more compelling given the continued increase in US disease incidence since the early $2000 \mathrm{~s} .{ }^{38}$ Inaccurate CDI diagnostics continue to confound clinical management; timely diagnosis is essential to effectively manage patients and prevent transmission. ${ }^{41,42}$

We acknowledge certain methodologic limitations. First, many of our clinical input variables are variable in the published literature. ${ }^{43}$ Second, there are no standardized health state utility estimates for CDI patients; we therefore extrapolated from other causes of diarrhea, specifically colitis as previously reported. ${ }^{44,45}$ Our sensitivity analyses showed that the ICERs were insensitive to variation of this parameter. Third, our model population was limited to adults aged 65 years old, the average age of CDI patients. ${ }^{2,3}$ The results of our sub-analyses for 75 and 85 years old cohorts were the same as for 65 year olds. Additionally, the model population was limited to patients who had a CDI diagnostic test at outpatient setting, and may not be applicable to hospitalized patients. Lastly, our decision tree model includes pre-defined estimates of time patients spent in different health states after $\mathrm{CDI}$. The conclusions, however, remained the same when predefined time period varied.

Corresponding Author: Joel W. Hay, PhD; Leonard D. Schaeffer Center for Health Policy and Economics, University of Southern California, Los Angeles, CA, USA (e-mail: jhay@usc.edu).

\section{Compliance with Ethical Standards:}

Conflict of Interest: The authors declare that they do not have conflict of interest.

\section{REFERENCES}

1. Lessa FC, Mu Y, Bamberg WM, Beldavs ZG, Dumyati GK, Dunn JR, et al. Burden of Clostridium difficile infection in the United States. N Engl J Med 2015;372(9):825-34. https://doi.org/10.1056/NEJMoa1408913

2. Evans CT, Safdar N. Current trends in the epidemiology and outcomes of Clostridium difficile infection. Clin Infect Dis 2015;60 Suppl 2:S66-71. https://doi.org/10.1093/cid/civ140

3. Lucado J, Gould C, Elixhauser A. Clostridium difficile infections (CDI) in hospital stays, 2009. HCUP Statistical Brief \# 124. Agency for Healthcare Research and Quality, Rockville, MD. 2012. https://www.hcup-us.ahrq. gov/reports/statbriefs/sb124.pdf. Accessed 16 August 2019.

4. Centers for Disease Control and Prevention. Antibiotic resistance threats in the United States, 2013. http://www.cdc.gov/drugresistance/threatreport-2013/. Accessed 16 August 2019.

5. McDonald LC, Gerding DN, Johnson S, Bakken JS, Carroll KC, Coffin SE, et al. Clinical practice guidelines for Clostridium difficile infection in adults and children: 2017 update by the Infectious Diseases Society of America (IDSA) and Society for Healthcare Epidemiology of America (SHEA). Clin Infect Dis 2018;66(7):e1-e48.

6. Schroeder LF, Robilotti E, Peterson LR, Banaei N, DW D. Economic evaluation of laboratory testing strategies for hospital-associated Clostridium difficile infection. J Clin Microbiol 2014;52(2):489-96.

7. Verhoye $\mathbf{E}$, Vandecandelaere $\mathbf{P}$, De Beenhouwer $\mathbf{H}$, Coppens $\mathbf{G}$, Cartuyvels R, Van den Abeele A, et al. A hospital-level cost-effectiveness analysis model for toxigenic Clostridium difficile detection algorithms. J Hosp Infect 2015;91(2): 123-8. https://doi.org/10.1016/j.jhin.2015.06.001

8. Vasoo S, Stevens J, Portillo L, Barza R, Schejbal D, Wu MM, et al. Cost-effectiveness of a modified two-step algorithm using a combined glutamate dehydrogenase/toxin enzyme immunoassay and real-time PCR for the diagnosis of Clostridium difficile infection. J Microbiol Immunol Infect 2014;47(1):75-8. https://doi.org/10.1016/j.jmii.2012. 07.008

9. Bartsch SM, Umscheid CA, Nachamkin I, Hamilton $\mathbf{K}$, Lee BY. Comparing the economic and health benefits of different approaches to diagnosing Clostridium difficile infection. Clin Microbiol Infect. 2015;21(1):77 e1-9. https://doi.org/10.1016/j.cmi.2014.07.002

10. Gold MR, Siegel JE, Russell LB, Weinstein MC, eds. Cost-effectiveness in health and medicine. New York: Oxford University Press; 1996.

11. Neumann PJ, Sanders GD, Russell LB, Siegel JE, Ganiats TG, eds. Cost-effectiveness in health and medicine. 2nd ed. New York: Oxford University Press; 2016.

12. CDC Life Table 2015. https://www.cdc.gov/nchs/data/hus/hus 16 . pdf\#015. Accessed 16 August 2019.

13. Briggs A, Schulper MJ, Claxton K. Decision modelling for health economic evaluation. 2006.

14. Neumann PJ, Cohen JT, Weinstein MC. Updating costeffectiveness-the curious resilience of the \$50,000-per-QALY threshold. N Engl J Med 2014;371(9):796-7. https://doi.org/10.1056/ NEJMp1405158

15. Loraine AW, Samantha C, Daniel G, He W. $65+$ in the United States: 2010. Special Studies. Current Population Reports. U.S. Department of Health and Human Services. 2014. https://www.census.gov/content/ dam/Census/library/publications/2014/demo/p23-212.pdf. Accessed 16 August 2019.

16. Jones T, McMillian M, Scallan E, Frenzen P, Cronquist A, Thomas S, et al. A population-based estimate of the substantial burden of diarrhoeal disease in the United States; FoodNet, 1996-2003. Epidemiol Infect 2007; 135(2):293-301.

17. Abrahamian FM, Talan DA, Krishnadasan A, Citron DM, Paulick AL, Anderson LJ, et al. Clostridium difficile infection among US emergency department patients with diarrhea and no vomiting. Ann Emerg Med. 2017;70(1): 19-27. e4.

18. Cornely OA, Crook DW, Esposito R, Poirier A, Somero MS, Weiss K, et al. Fidaxomicin versus vancomycin for infection with Clostridium difficile in Europe, Canada, and the USA: a double-blind, non-inferiority, randomised controlled trial. Lancet Infect Dis 2012;12(4):281-9. https:// doi.org/10.1016/s1473-3099(11)70374-7 
19. Gravel D, Miller M, Simor A, Taylor G, Gardam M, McGeer A, et al. Health care-associated Clostridium difficile infection in adults admitted to acute care hospitals in Canada: a Canadian Nosocomial Infection Surveillance Program Study. Clin Infect Dis 2009;48(5):568-76.

20. Appaneal HJ, Caffrey AR, Beganovic M, Avramovic S, LaPlante KL editors. Predictors of Mortality Among a National Cohort of Veterans with Recurrent Clostridium difficile Infection. Open forum infectious diseases. 2018: Oxford University Press US.

21. Dallas KB, Condren A, Divino CM. Life after colectomy for fulminant Clostridium difficile colitis: a 7-year follow up study. Am J Surg 2014;207(4):533-9. https://doi.org/10.1016/j.amjsurg.2013.04.008

22. Seder CW, Villalba MR, Jr., Robbins J, Ivascu FA, Carpenter CF, Dietrich M, et al. Early colectomy may be associated with improved survival in fulminant Clostridium difficile colitis: an 8-year experience. Am J Surg 2009;197(3):302-7. https://doi.org/10.1016/j.amjsurg.2008. 11.001

23. Kasper AM, Nyazee HA, Yokoe DS, Mayer J, Mangino JE, Khan YM, et al. A multicenter study of Clostridium difficile infection-related colectomy, 2000-2006. Infect Control Hosp Epidemiol 2012;33(5):470-6. https://doi.org/10.1086/665318

24. Johnson S, Louie TJ, Gerding DN, Cornely OA, Chasan-Taber S, Fitts D, et al. Vancomycin, metronidazole, or tolevamer for Clostridium difficile infection: results from two multinational, randomized, controlled trials. Clin Infect Dis 2014;59(3):345-54. https://doi.org/10.1093/cid/ciu313

25. Thomas J. Louie, Mark A. Miller, Kathleen M. Mullane, Karl Weiss, Arnold Lentnek, Yoav Golan, et al. Fidaxomicin versus vancomycin for Clostridium difficile infection. N Engl J Med 2011;364.

26. Lynne V. McFarland, Gary W. Elmer, Surawicz CM. Breaking the cycle: treatment strategies for 163 cases of recurrent Clostridium difficile disease. Am J Gastroenterol. 2002;97(7).

27. Mattila E, Arkkila P, Mattila PS, Tarkka E, Tissari P, Anttila VJ. Rifaximin in the treatment of recurrent Clostridium difficile infection. Aliment Pharmacol Ther 2013;37(1):122-8. https://doi.org/10.1111/apt. 12111

28. Rokas KE, Johnson JW, Beardsley JR, Ohl CA, Luther VP, Williamson JC. The addition of intravenous metronidazole to oral vancomycin is associated with improved mortality in critically ill patients with Clostridium difficile infection. Clin Infect Dis 2015;61(6):934-41. https://doi.org/ $10.1093 / \mathrm{cid} / \mathrm{civ} 409$

29. Crobach MJ, Planche T, Eckert C, Barbut F, Terveer EM, Dekkers OM, et al. European Society of Clinical Microbiology and Infectious Diseases: update of the diagnostic guidance document for Clostridium difficile infection. Clin Microbiol Infect 2016;22 Suppl 4:S63-81. https://doi.org/ 10.1016/j.cmi.2016.03.010

30. Timothy D Planche, Kerrie A Davies, Pietro G Coen, John M Finney, Irene M Monahan, Kirsti A Morris, et al. Differences in outcome according to Clostridium difficile testing method: a prospective multicentre diagnostic validation study of $\mathrm{C}$ difficile infection. Lancet Infect Dis 2013(13):936-45. https://doi.org/10.1016/S1473-3099(13) 70200-7

31. Rice JA. Mathematical statistics and data analysis. 2003.

32. Kanchanaraksa $\mathbf{S}$. Evaluation of diagnostic and screening tests: validity and reliability. http://ocw.jhsph.edu/courses/fundepi/pdfs/lecture11. pdf. Accessed 16 August 2019.
33. Jia H, Lubetkin EI. Impact of nine chronic conditions for US adults aged 65 years and older: an application of a hybrid estimator of qualityadjusted life years throughout remainder of lifetime. Qual Life Res Int J Qual Life Asp Treat Care Rehab. 2016;25(8):1921-9. https://doi.org/10. 1007/s11136-016-1226-5

34. Gibson PR, Vaizey C, Black CM, Nicholls R, Weston AR, Bampton P, et al. Relationship between disease severity and quality of life and assessment of health care utilization and cost for ulcerative colitis in Australia: a cross-sectional, observational study. J Crohns Colitis 2014;8(7):598-606. https://doi.org/10.1016/j.crohns.2013.11.017

35. Gani F, Makary MA, Wick EC, Efron JE, Fang SH, Safar B, et al. Bundled payments for surgical colectomy among Medicare enrollees: potential savings vs the need for further reform. JAMA Surg 2016;151(5):e160202. https://doi.org/10.1001/jamasurg.2016.0202

36. U.S. Department of Veterans Affairs. Drug pharmaceutical prices. https://www.fss.va.gov/. Accessed 16 August 2019.

37. Schneider KM, O'Donnell BE, Dean D. Prevalence of multiple chronic conditions in the United States' Medicare population. Health Qual Life Outcomes 2009;7:82. https://doi.org/10.1186/1477-7525-7-82

38. Li R, Lu L, Lin Y, Wang M, Liu X. Efficacy and safety of metronidazole monotherapy versus vancomycin monotherapy or combination therapy in patients with Clostridium difficile infection: a systematic review and meta-analysis. PLoS One 2015;10(10):e0137252. https://doi.org/10. 1371/journal.pone.0137252

39. Bureau of Labor Statistics, United States Department of Labor. www.bls. gov/data/. Accessed 16 August 2019.

40. World Health Organization. Cost-effectiveness thresholds. http://www. who.int/bulletin/volumes/94/12/15-164418/en/. Accessed 16 August 2019.

41. Burnham CA, Carroll KC. Diagnosis of Clostridium difficile infection: an ongoing conundrum for clinicians and for clinical laboratories. Clin Microbiol Rev 2013;26(3):604-30. https://doi.org/10.1128/CMR.0001613

42. Smits WK, Lyras D, Lacy DB, Wilcox MH, Kuijper EJ. Clostridium difficile infection. Nat Rev Dis Primers 2016;2:16020. https://doi.org/10. 1038/nrdp.2016.20

43. Sheitoyan-Pesant C, Abou Chakra CN, Pepin J, Marcil-Heguy A, Nault V, Valiquette L. Clinical and Healthcare burden of multiple recurrences of Clostridium difficile infection. Clin Infect Dis 2016;62(5):574-80. https://doi.org/10.1093/cid/civ958

44. Lapointe-Shaw L, Tran KL, Coyte PC, Hancock-Howard RL, Powis J, Poutanen SM, et al. Cost-effectiveness analysis of six strategies to treat recurrent Clostridium difficile infection. PLoS One 2016;11(2):e0149521. https://doi.org/10.1371/journal.pone.0149521

45. Konijeti GG, Sauk J, Shrime MG, Gupta M, Ananthakrishnan AN. Cost-effectiveness of competing strategies for management of recurrent Clostridium difficile infection: a decision analysis. Clin Infect Dis 2014;58(11):1507-14. https://doi.org/10.1093/cid/ciu128

Publisher's Note Springer Nature remains neutral with regard to jurisdictional claims in published maps and institutional affiliations. 